\title{
A COPA DO MUNDO DE FUTEBOL 2014 NA REGIÃO SUL DO BRASIL: UMA ANÁLISE DOS ESPAÇOS DA CIDADE
}

\author{
THE 2014 FOOTBALL WORLD CUP IN SOUTHERN BRAZIL: AN ANALYSIS OF \\ CITY SPACES
}

\author{
LA COPA MUNDIAL DE FÚTBOL 2014 EN LA REGIÓN SUR DE BRASIL: UN \\ ANÁLISIS DE LOS ESPACIOS DE LA CIUDAD
}

\author{
Emília Amélia Pinto Costa Silva*, Simone Rechia*, Javier Olivera Betránn
}

\section{Palavras-chave Desenvolvimento da comunidade. Esportes. \\ Cidades.}

Keywords Community development. Sports.

Cities.

Palabras clave Desarrollo de la comunidad. Deportes. Ciudades.
Resumo: 0 objetivo desta pesquisa foi identificar as transformações das cidades do sul do Brasil que foram sede da Copa do Mundo de Futebol 2014, principalmente no que se refere aos espaços de lazer e esporte. Trata-se de uma pesquisa descritiva de abordagem qualitativa. Os espaços delimitados foram os espaços e equipamentos do entorno dos estádios Joaquim Américo, em Curitiba/PR, e Beira-Rio, em Porto Alegre/ RS. Participaram da entrevista 25 sujeitos da cidade de Curitiba e 30 de Porto Alegre. Os resultados indicam que as mudanças se restringem aos estádios que são privados e algumas melhorias dos espaços que estão próximos aos espaços.

Abstract: The aim of this research was to identify changes in southern Brazilian cities that hosted the 2014 Football World Cup, especially with regard to leisure and sporting spaces. It is a descriptive qualitative study. Spaces and equipment chosen were located near the Joaquim Américo stadium in Curitiba, PR, and the Beira-Rio stadium in Porto Alegre, RS. Twenty-five subjects from the city of Curitiba and 30 from Porto Alegre were interviewed. The results indicate that changes were restricted to private stadiums and to some improvements in areas that are near the spaces.

Resumen: El objetivo de esta investigación fue identificar las transformaciones de las ciudades del sur de Brasil que fueron sede de la Copa Mundial de Fútbol de 2014, especialmente en lo que se refiere a los espacios de ocio y deporte. Es una descriptiva con un abordaje cualitativo. Los espacios delimitados fueron los locales y equipos que se encuentran en los alrededores de los estadios Joaquim Américo, en Curitiba, Paraná y Beira-Rio, en Porto Alegre, Rio Grande do Sul. Participaron en la entrevista 25 individuos de la ciudad de Curitiba y 30 de Porto Alegre. Los resultados indican que los cambios se limitan a los estadios, que son privados, y algunas mejoras en las áreas que están cerca de esos espacios.
* Universidade Federal do Paraná Curitiba, PR, Brasil.

E-mail: milapcosta@hotmail.com

** Institut Nacional d'Educació Física de Catalunya. Barcelona, España. E-mail: jolivera@gencat.cat

Recebido em: 11-06-2015 Aprovado em: 04-12-2015 (c) (1) (8) Licence 


\section{INTRODUÇÃOO}

A vinda da Copa do Mundo de 2014 para este país poderia ser uma oportunidade para a reestruturação das cidades-sede contempladas, no que tange às questões da mobilidade, segurança, moradia, estádios, espaços públicos, dentre outras, visto que os megaeventos esportivos têm o poder de movimentar as cidades, no que se refere à infraestrutura, economia, política e à população no geral, havendo uma direção para o esporte espetáculo interrelacionado com estes elementos. No entanto, essa expectativa não foi atendida, pois, em algumas cidades, por exemplo, as prefeituras ou os estádios não assumiram as contrapartidas propostas inicialmente, as obras dos estádios e seu entorno não ficaram totalmente prontas, entre outros problemas e atrasos.

O processo de espetacularização é uma estratégia de marketing urbano, que tem como um dos intuitos a intervenção nas estruturas da cidade a fim de construir uma nova imagem (JACQUES, 2003). No entanto, geralmente, não são discutidas as mudanças nas estruturas de lazer e esporte, mesmo sabendo-se que esses âmbitos nem sempre são o foco principal das intervenções realizadas para esse tipo de evento.

Desta forma, o presente estudo foi norteado a partir do seguinte questionamento: quais as transformações que ocorreram nos espaços e equipamentos de lazer e esporte das cidades do sul do Brasil que foram sede da Copa do Mundo de Futebol 2014 ?

Ressalta-se que nem todos os megaeventos esportivos implicam legados positivos, apesar dos altos investimentos, principalmente nas estruturas físicas. Além disso, destaca-se que nem todos os legados podem ser planejados como um todo, todavia, os políticos trazem os megaeventos para cidade e/ou país para gerar otimismo, atração de recursos e o aceleramento do desenvolvimento das cidades (PREUSS, 2007).

As características principais de um megaevento esportivo são a capacidade de atrair espectadores e audiência do mundo todo e as repercussões ou impactos que podem causar nas cidades ou no país que o recebe (HORNE; MANZENREITER, 2006). O interesse em sediar um evento desse porte cresce gradativamente entre os países de todo o mundo. Organizar esse tipo de evento resulta em um objetivo-chave de muitos governos, visto que os megaeventos esportivos são considerados catalisadores de criação de valores para as economias dos países anfitriões (RADICCHI, 2012).

Ao mesmo tempo, há alguns países que tem resistência em sediar algum megaevento esportivo. A Suécia é um exemplo, pois decidiu acabar com a possibilidade de sediar os Jogos Olímpicos de inverno de 2022, para não utilizar o dinheiro público (EXAME, 2015). Isso também já aconteceu com o Brasil, que foi indicado para receber a Copa do Mundo de 1986, mas, na ocasião, o presidente Figueiredo recusou, pois as prioridades para 0 país eram outras (BRASIL- LIBERDADE E DEMOCRACIA, 2015). Ressalta-se que, embora alguns países recusem sediar os megaeventos esportivos, ainda é comum o interesse de outros em receber tais eventos.

Toda essa notoriedade que os megaeventos têm atualmente parte do exemplo que foram os Jogos Olímpicos em Barcelona, no ano de 1992 (BERNASCONI, 2013). De acordo com Bernasconi (2013), Barcelona foi um exemplo da importância do planejamento no período que antecede o evento e do legado que pode ficar, visto que, mesmo após mais 
de 20 anos de terem ocorrido os Jogos, os legados ainda são nítidos em várias partes da cidade. Principalmente nos espaços e equipamentos de esporte e lazer, visto que os usos desses espaços públicos foram potencializados a partir da variedade de espaços e dos usos principais e combinados presentes na cidade (RECHIA; BETRÁN, 2010). De fato, essas mudanças e ampliação das opções de lazer tiveram relação com a vinda dos Jogos Olímpicos de 1992.

Consideram-se os Jogos de 1992 como um exemplo positivo, e muitos países tentam se espelhar em Barcelona. No entanto, observa-se que os Jogos seguintes não tiveram tantos impactos econômicos positivos. No caso da Grécia, por exemplo, os altos custos e falta de rigor na fiscalização das verbas já alertavam para dificuldades futuras, que foi a crise de endividamento, que se difundiu pela zona do euro. A crise se estende até os dias atuais (ECONOMIA IG, 2015).

Um caso mais recente, falando da Copa do Mundo, é o da África do Sul. O estudo de Du Plessis, Venter e Polity (2010) apontam os efeitos econômicos, constatando que o PIB da África do Sul variou de $0,1 \%$ a 1,5\%. Outra informação ressalta que o PIB teve 0 acréscimo de no máximo 0,3\%, não sendo significativo ao comparar com os gastos realizados (PASSOS, 2014). Todavia, Passos afirma que a FIFA teve lucros com o evento, e que, comparado com a Copa de 2006, houve um aumento de $48 \%$ de ganho para instituição. Conforme 0 autor, a FIFA arrecadou na África 8,9 bilhões de reais, tendo como lucro final 4,9 bilhões.

Assim como qualquer cidade, Barcelona também passou por dificuldades. Antes da realização dos Jogos, a cidade tinha déficit nas finanças e muitas dívidas. No entanto, partiu do planejamento de recuperar edifícios de qualidade, como equipamentos culturais, espaços públicos, animação sociocultural, apoio a iniciativas sociais, como também econômicas e preparação de projetos de reabilitação (BORJA, 2010). Foi a partir desses projetos que tal candidatura foi anunciada e, conforme Borja (2010), a cidade teve a capacidade de desenvolver grandes e complexos projetos. Mascarenhas (2012, p. 41) ressalta que, assim como em Barcelona, no Brasil a expectativa é de que "os Jogos imprimam à feitura das cidades-sede verdadeiros saltos de inovação em produtos, serviços, estilos de vida, formas culturais e institucionais". Isso se trata tanto da Copa do Mundo realizada em 2014 como das Olimpíadas 2016. No entanto, passado um ano da realização da Copa do Mundo já é possível identificar alguns dos seus impactos, positivos e negativos, que serão tratados no tópico dos resultados do presente artigo.

Todavia, no Brasil já se tinha o exemplo do Pan-Americano, realizado no ano de 2007, quando as oportunidades não foram aproveitadas completamente, visto as obras inacabadas, o alto custo e a falta de perspectiva de uso das instalações construídas (BERNASCONI, 2013). Ressalta-se que muitas delas não foram/serão utilizadas para os Jogos Olímpicos em 2016, por exemplo. Em relação à Copa do Mundo de Futebol 2014, recentemente realizada, ainda está sendo analisado o que de fato ficará como legado positivo e negativo. Talvez seja preciso um período maior para analisar os impactos de receber três grandes eventos em menos de dez anos.

Houve uma euforia entre os brasileiros quando se ganhou o direito de sediar a Copa do Mundo de Futebol 2014. Contudo, o número de pessoas que apoiava o evento foi caindo à medida que se aproximava o evento. Conforme o Datafolha (2014), um ano após o anúncio de 
que o Brasil sediaria a Copa, em novembro de 2008, 79\% dos brasileiros apoiavam o evento, já em julho de 2013, o número caiu para 65\% e em fevereiro de 2014, para 52\%. Para Conchas (2014), a preparação que antecede um megaevento esportivo, não só para o Brasil, mas para qualquer outro país, exige desafios complexos de ordem econômica, política e social. Carvalho (2013, p. 84) ressalta: "da propositura de intenções até a realidade dos fatos póseventos, efetivando o real legado dos megaeventos esportivos, existe uma distância, que não é somente temporal, ela envolve questões técnicas, políticas, sociais e econômicas". Ou seja, considera-se um grande desafio sediar um megaevento esportivo, devido à sua amplitude, às demandas tangíveis que são geradas e aos investimentos que são realizados. Também se considera complexo devido aos impactos intangíveis causados, como: a expectativa do cidadão, o sentimento de pertencimento, o valor simbólico que envolve o futebol no Brasil, entre outros.

Uma das expectativas é de que, com os megaeventos esportivos no Brasil, sejam construídos e potencializados diferentes espaços e equipamentos de lazer e esporte (RECHIA; SILVA, 2013). Por isso a importância de desenvolver estudos relacionados aos espaços e equipamentos de lazer e os megaeventos esportivos, visto que para a Educação Física é interessante entender como esses fenômenos podem influenciar o planejamento das cidades.

Diante do contexto, 0 artigo tem o objetivo de identificar as transformações das cidades do sul do Brasil que foram sede da Copa do Mundo de Futebol 2014, principalmente no que se refere aos espaços de lazer e esporte.

\section{METODOLOGIA}

A pesquisa é do tipo descritiva de campo, com abordagem qualitativa. $O$ estudo foi desenvolvido nas cidades-sede da Copa do Mundo de Futebol 2014 da Região Sul do Brasil, Curitiba/PR e Porto Alegre/RS. Os espaços delimitados foram os espaços e equipamentos do entorno dos estádios Joaquim Américo, em Curitiba, e do Beira-Rio, em Porto Alegre. Esses espaços foram delimitados considerando um raio de $2 \mathrm{~km}$. Essa opção se deu pelo fato de que as pessoas que vivem e frequentam esse entorno cotidianamente compreendem, assim, o processo de transformação do local. Deste modo proporcionou-se um maior aprofundamento sobre o tema, respeitando-se os critérios de inclusão estabelecidos para a pesquisa.

A coleta de dados foi realizada no período que antecedeu a Copa do Mundo de Futebol 2014, entre os meses de março a junho de 2014, em diferentes dias de semana e final de semana, no horário da manhã ( $8 \mathrm{~h}$ às $12 \mathrm{~h}$ ) e da tarde (14h às 18h), tanto na cidade de Curitiba como em Porto Alegre.

Inicialmente, foram feitas observações sistemáticas nos espaços delimitados para 0 estudo. O roteiro das observações utilizado foi elaborado pelo Grupo de Estudos e Pesquisa em Lazer, Espaço e Cidade - Geplec e adaptado para o presente estudo. O intuito foi identificar as condições dos espaços e equipamentos de lazer e esporte e suas respectivas formas de uso. 
Além disso, a observação gerou subsídios e apropriação para construir o roteiro de entrevista semiestruturada que foi realizada posteriormente.

A amostra caracterizou-se por acidental e foi utilizado o critério de saturação para 0 fechamento. Sendo assim, participaram do estudo 55 sujeitos ( 25 da cidade de Curitiba e 30 indivíduos de Porto Alegre). Foram incluídos os indivíduos que frequentam as proximidades dos estádios da Região Sul do Brasil selecionados para Copa do Mundo. Foram excluídos indivíduos com faixa etária inferior a 18 anos, que não residem nas cidades selecionadas e não se interessaram em participar da pesquisa de forma voluntária.

$O$ roteiro de entrevista semiestruturada continha questões fechadas e abertas acerca das mudanças estruturais concernentes às obras da Copa do Mundo de Futebol, opiniões sobre o evento na cidade e participação dos cidadãos no processo de planejamento desse megaevento. Para melhor veracidade das falas dos sujeitos pesquisados, as entrevistas foram registradas por meio de um gravador e tiveram duração, em média, de 15 min.

As entrevistas foram transcritas na íntegra e, em seguida, submetidas ao software Analysis of Qualitative Data - AQUAD, que identificou a frequência absoluta das palavras e auxiliou na construção das categorias, as quais foram apreciadas a partir da análise de conteúdo. As questões fechadas foram analisadas por meio da estatística descritiva, na qual os resultados foram apresentados a partir do programa STATA v.13. Para a construção dos diagramas foi utilizado o software GoDiagram Express, versão 2.6.2.

Este estudo foi aprovado pelo Comitê de Ética em Pesquisa com Seres Humanos do Hospital do Trabalhador/SES/PR, número do parecer 607.680, conforme a resolução no 466/12 do Conselho Nacional de Saúde (BRASIL, 2012). Ressalta-se que as prefeituras das cidades de Curitiba e de Porto Alegre permitiram a realização das entrevistas nos espaços públicos selecionados, por meio da Carta de Anuência. Os participantes do estudo foram esclarecidos quanto aos objetivos, procedimentos, privacidade das informações e assinaram um Termo de Consentimento Livre e Esclarecido.

\section{RESULTADOS}

Os resultados foram divididos em três etapas. Primeiro será apresentado o perfil sociodemográfico dos sujeitos frequentadores. Em um segundo momento, a concepção dos sujeitos em relação às modificações que ocorreram na cidade e, por fim, foi elaborada a categoria analítica, que consiste em apresentar as mudanças que ocorreram nas cidades-sede a partir da opinião dos participantes da pesquisa e das observações realizadas.

A Tabela 1 apresenta o perfil sociodemográfico dos frequentadores dos espaços delimitados para o presente estudo. Em ambas as cidades prevaleceu o sexo masculino; $40 \%$ dos entrevistados de Curitiba concluíram o ensino médio, e na cidade de Porto Alegre $11 \%$ concluíram o ensino superior. A maioria dos indivíduos de Curitiba $(47,83 \%)$ frequenta 0 espaço pesquisado a menos de cinco anos, e em Porto Alegre, 33,33\% frequentam entre 21 a 30 anos (Tabela 1). 
Tabela 1 - Caracterização sociodemográfica e utilização do entorno dos estádios das cidades de Curitiba e Porto Alegre (2014).

\begin{tabular}{|c|c|c|c|c|c|}
\hline \multirow{2}{*}{\multicolumn{2}{|c|}{ Variável }} & $\mathrm{n}$ & $\%$ & $\mathrm{n}$ & $\%$ \\
\hline & & \multicolumn{2}{|c|}{ Curitiba } & \multicolumn{2}{|c|}{ Porto Alegre } \\
\hline \multicolumn{6}{|l|}{ Sexo } \\
\hline & Homem & 14 & 56,0 & 16 & 53,3 \\
\hline & Mulher & 11 & 44,0 & 14 & 46,7 \\
\hline \multicolumn{6}{|l|}{ Idade } \\
\hline & 18 a 29 anos & 11 & 44,0 & 16 & 53,3 \\
\hline & 30 a 39 anos & 7 & 28,0 & 10 & 33,3 \\
\hline & 40 a 49 anos & 5 & 20,0 & - & - \\
\hline & Mais de 50 anos & 2 & 8,0 & 4 & 13,3 \\
\hline \multicolumn{6}{|c|}{ Escolaridade } \\
\hline & Ensino fundamental I incompleto & 2 & 8,0 & - & - \\
\hline & Ensino fundamental I completo & 1 & 4,0 & - & - \\
\hline & Ensino fundamental II incompleto & 1 & 4,0 & - & - \\
\hline & Ensino fundamental II completo & 2 & 8,0 & 2 & 6,7 \\
\hline & Ensino médio incompleto & 1 & 4,0 & - & - \\
\hline & Ensino médio completo & 10 & 40,0 & 10 & 33,3 \\
\hline & Superior incompleto & 2 & 8,0 & 7 & 23,3 \\
\hline & Superior completo & 6 & 24,0 & 11 & 36,3 \\
\hline \multicolumn{6}{|c|}{ Tempo que frequenta o espaço } \\
\hline & Até 5 anos & 11 & 47,83 & 5 & 18,52 \\
\hline & 6 a 10 anos & 6 & 26,09 & 2 & 7,41 \\
\hline & 11 a 20 anos & 3 & 13,04 & 6 & 22,22 \\
\hline & 21 a 30 anos & 1 & 4,35 & 9 & 33,33 \\
\hline & 31 a 40 anos & 2 & 8,70 & 3 & 11,11 \\
\hline & 41 a 55 anos & - & - & 2 & 7,41 \\
\hline \multicolumn{6}{|c|}{ Renda } \\
\hline & 1 a 2 salários mínimos & 16 & 64,0 & 16 & 53,33 \\
\hline & 3 a 4 salários mínimos & 4 & 16,0 & 4 & 13,33 \\
\hline & 5 a 6 salários mínimos & 3 & 12,0 & 3 & 10,00 \\
\hline & Mais de 7 salários mínimos & 2 & 8,0 & 7 & 23,33 \\
\hline Total & & 25 & 100,0 & 30 & 100,0 \\
\hline
\end{tabular}

Foi perguntado aos entrevistados se eles concordavam ou discordavam de algumas questões referente às mudanças estruturais das cidades para a realização da Copa do Mundo de Futebol. Quando indagados se a Copa do Mundo beneficiaria exclusivante os moradores próximos dos espaços em que ocorreram os jogos, $72 \%$ dos entrevistados de Curitiba e $66,7 \%$ de Porto Alegre discordaram dessa afirmação. Sobre se os frequentadores foram informados das modificações que ocorreram nas cidades-sede, $80 \%$ dos sujeitos de Curitiba e $60 \%$ de Porto Alegre ressaltaram que não concordam com essa afirmação. Da mesma forma, não concordaram ( $80 \%$ Curitiba e $76,7 \%$ Porto Alegre) que são cidadãos participantes no processo de planejamento dos megaeventos esportivos no Brasil (Tabela 2).

Por outro lado, quando indagados se a Copa do Mundo de Futebol traria mais benefício para a cidade onde o entrevistado vive, $60 \%$ dos sujeitos de Curitiba e $73,3 \%$ de Porto Alegre concordaram. Do mesmo modo, 52\% dos entrevistados de Curitiba e 70\% de Porto Alegre 
responderam que os impactos econômicos e ambientais advindos dos megaeventos esportivos seriam positivos para a cidade.

Tabela 2 - Modificações que ocorreram nas cidades de Curitiba e Porto Alegre (2014).

\begin{tabular}{|c|c|c|c|c|}
\hline \multirow{2}{*}{ Variável } & $n$ & $\%$ & $\mathrm{n}$ & $\%$ \\
\hline & \multicolumn{2}{|c|}{ Curitiba } & \multicolumn{2}{|c|}{ Porto Alegre } \\
\hline \multicolumn{5}{|c|}{ Benefícios da vizinhança } \\
\hline Concorda & 7 & 28,0 & 10 & 33,3 \\
\hline Discorda & 18 & 72,0 & 20 & 66,7 \\
\hline \multicolumn{5}{|c|}{ Informação das modificações } \\
\hline Concorda & 5 & 20,0 & 12 & 40,0 \\
\hline Discorda & 20 & 80,0 & 28 & 60,0 \\
\hline \multicolumn{5}{|c|}{ Cidadão participante } \\
\hline Concorda & 5 & 20,0 & 7 & 23,3 \\
\hline Discorda & 20 & 80,0 & 23 & 76,7 \\
\hline \multicolumn{5}{|c|}{ Benefícios gerais para a cidade } \\
\hline Concorda & 15 & 60,0 & 22 & 73,3 \\
\hline Discorda & 10 & 40,0 & 8 & 26,7 \\
\hline \multicolumn{5}{|c|}{ Impactos econômicos e ambientais } \\
\hline Concorda & 13 & 52,0 & 21 & 70,0 \\
\hline Discorda & 12 & 48,0 & 9 & 30,0 \\
\hline Total & 25 & 100,0 & 30 & 100,0 \\
\hline
\end{tabular}

A técnica de análise de conteúdo possibilitou a construção da categoria Mudanças positivas e negativas nas cidades-sede (Figura 1), representada na cor cinza-escuro. As subcategorias assinaladas na cor cinza-claro estão relacionadas às concepções dos sujeitos concernentes às transformações positivas/negativas que ocorreram nas cidades pesquisadas.

Figura 1 - Mudanças positivas e negativas nas cidades-sede de Curitiba e Porto Alegre (2014).

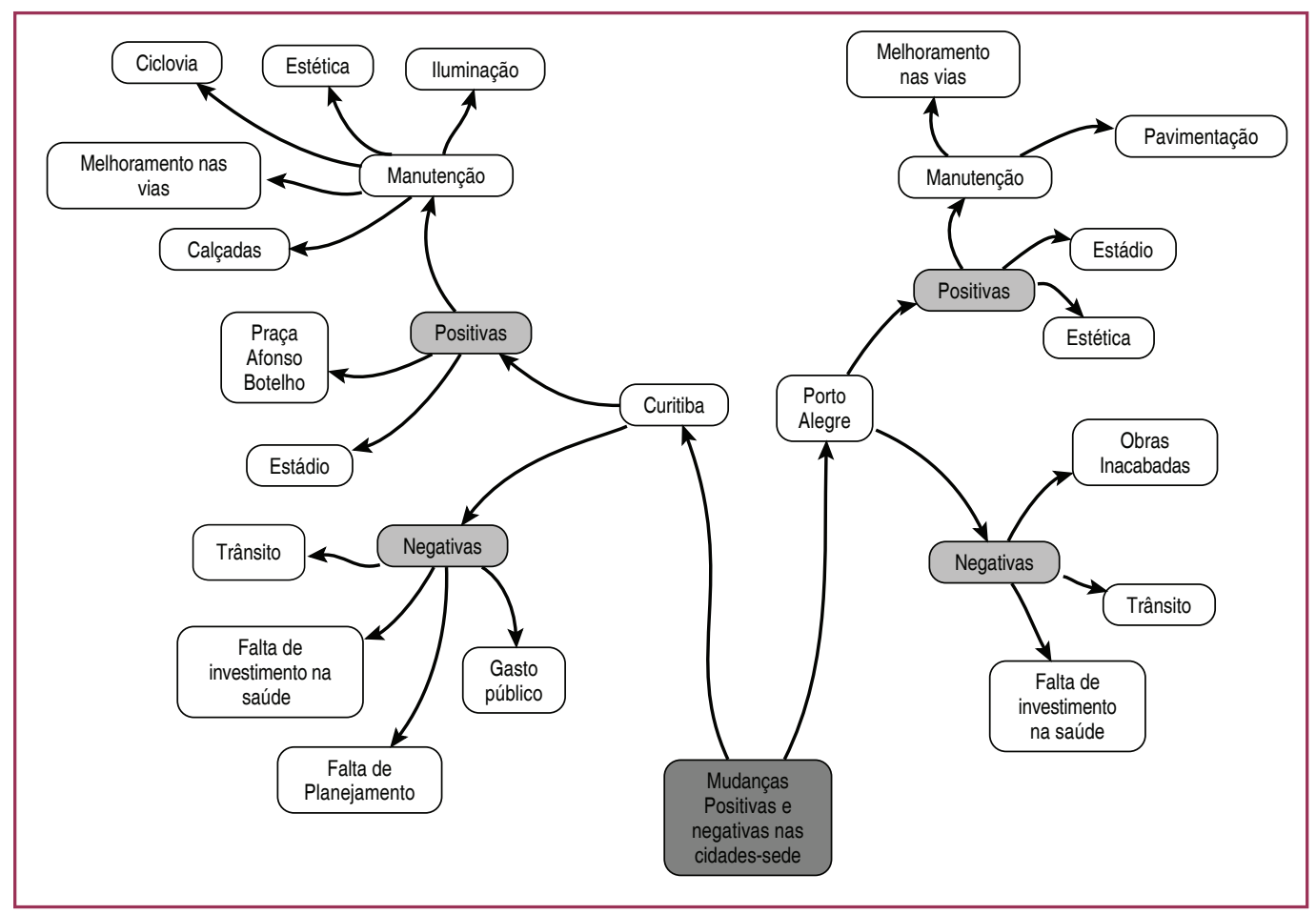




\section{DISCUSSÃO}

Analisando-se os resultados referentes ao perfil sociodemográfico, percebe-se que outros estudos também realizados em espaços públicos de lazer encontraram maior evidência do sexo masculino (COHEN et al., 2007; SANTOS, 2007; COLLET et al., 2008; CASSOU, 2009; SILVA; PETROSKI; REIS, 2009; ROTTA; PIRES, 2010). No tocante à idade, foi observado em ambas as cidades que a maioria dos entrevistados é adulto jovem. No estudo de Cohen et al. (2007), 43\% dos pesquisados eram adultos e na pesquisa de Silva (2011) a maior parte dos entrevistados tinha entre 19 a 34 anos.

Em Porto Alegre, a maior parte dos sujeitos entrevistados frequenta o espaço delimitado para o presente estudo há mais tempo, quando comparados com os sujeitos de Curitiba. Todavia, isso não é um fator que pode interferir na presente análise, visto que foi observado e considerado que os entrevistados da cidade de Curitiba também tinham domínio quanto ao assunto em questão.

Em relação às modificações que ocorreram nas cidades, foi questionado se os indivíduos concordavam ou discordavam. Neste caso, primeiramente, os sujeitos destacaram que as transformações que ocorrem na cidade pela realização da Copa do Mundo não beneficiarão exclusivamente a população que vive próxima ao estádio. Com essa questão, pode-se fazer uma relação com o explanado em uma entrevista com Olga Firkowski (2014). Quando questionaram a autora se as obras da cidade de Curitiba estavam priorizando o público externo, ou seja, beneficiando mais o megaevento do que o cotidiano da cidade, a autora alegou que "as obras gerais de infraestrutura saíram da pauta e entraram as intervenções no corredor que liga o aeroporto ao estádio, passando pela rodoferroviária. Pensa-se, sobretudo, no turista". Em uma pesquisa realizada em Porto Alegre, foi questionado se a Copa do Mundo teve algum resultado positivo na cidade, e, no total de 134 entrevistados, 72 alegaram que não (GRAEF, 2015). A mesma pesquisa também questionou se as obras da Copa valeram a pena para a comunidade, 55 sujeitos responderam que sim e 72, que não.

Esses projetos de estruturas físicas, geralmente, são aqueles próximos aos estádios ou no caminho para se chegar até ele. Observa-se, portanto, que podem beneficiar mais os sujeitos que frequentam essas áreas, mas, ao mesmo tempo, pode-se dizer que o benefício maior é por parte dos turistas. Por outro lado, um dos pontos positivos de sediar um megaevento esportivo é que os projetos de desenvolvimento urbano (como de mobilidade urbana, transporte público, melhoria nas vias, nos espaços de lazer e esporte e na hotelaria) que já haviam sido planejados em longo prazo, sejam executados em um tempo mais curto (SMITH, 2012).

No que diz respeito ao acesso de informação, os sujeitos (80\% dos sujeitos de Curitiba e $60 \%$ de Porto Alegre) do presente estudo responderam que não foram informados das modificações que estavam ocorrendo. Este caso ocorre principalmente com os indivíduos que são removidos das suas respectivas casas, esses, muitas vezes, são os últimos a saber (ROLNIK, 2011). De acordo com Almeida (2013, p.1), a Constituição Federal, no art. 37, ressalta "o caráter educativo, informativo ou de orientação social da publicidade dos atos, programas, obras, serviços e campanhas dos órgãos públicos". Ou seja, está dentro da lei informar aos citadinos sobre as obras que serão realizadas. Ocorre que a população não tem acesso suficiente quanto aos seus direitos, como se informar e ainda como recorrer em determinadas situações. A consequência disso é que a participação popular se torna restrita, 
não havendo diálogo entre o poder público e a sociedade. Ainda de acordo com a pesquisa realizada em Porto Alegre (GRAEF, 2015), foi questionado se os sujeitos participaram dos processos públicos de decisão acerca o destino de suas respectivas casas, devido às obras da Copa, e 26 pessoas alegaram que sim e 108, que não.

Os entrevistados do presente estudo também alegaram que não se consideram cidadãos participantes (80\% Curitiba e $63,3 \%$ Porto Alegre). Isso pode ser em decorrência de que os projetos no Brasil, na maioria das vezes, são desenvolvidos e executados de forma autocrática, não dando espaço para os cidadãos opinarem e participarem do processo social, desenvolvendo, assim, seu papel de cidadão atuante nas decisões públicas.

Um exemplo desse caso está relacionado à parceria público-privada que foi realizada para reforma do Clube Atlético Paranaense. A reforma seria por meio dos recursos do Clube Atlético Paranaense e da União, por meio do Banco Nacional de Desenvolvimento Econômico e Social - BNDES. Desta forma, o estádio é privado e houve um investimento público, contudo o clube listou uma série de contrapartidas, descritas no Quadro 1.

\section{Quadro 1 - Contrapartidas do Clube Joaquim Américo}

a. Intensificação da parceria existente relativa às Escolinhas do Atlético Paranaense, em especial em áreas carentes;

b. Cedência, pelo período de cinco anos após o encerramento da Copa do Mundo, de um espaço junto à sua sede administrativa correspondente a $50 \%$ do total da área da sede, para instalar área da Secretaria Municipal de Esporte e Lazer;

c. Cedência, pelo período de 50 meses a partir da assinatura do convênio, de espaços para a realização de eventos de interesse do ESTADO e/ou do MUNICÍPIO, compatíveis com o espaço existente, e sem qualquer utilização dos espaços destinados à prática do futebol e de seus meios para treinamento, sem ônus, ressalvado o reembolso de despesas tais como iluminação, segurança e limpeza (considerando que o convênio foi assinado em setembro de 2010 e imaginando que as obras acabem em março de 2014, a contrapartida seria utilizada somente de março de 2014 a novembro de 2014);

d. Viabilização de espaço para a instalação de quiosques dos programas "LEVE CURITIBA" e "FEITO AQUI PARANÁ", como forma de apoiar o artesanato local;

e. Manutenção da parceria com o Instituto Municipal de Turismo quanto ao espaço para o ponto de parada da linha turismo na Arena do CAP:

f. Cedência, sem ônus, de dois camarotes na arena do CAP, sendo um para o MUNICÍPIO e outro para o ESTADO, para o desenvolvimento de programas e eventos de interesse municipal e estadual, pelo período de $\underline{50}$ meses a partir da assinatura do convênio (mesmo caso do item c);

g. Realização, ao final do ano, de um evento das escolinhas de futebol do clube, do qual participem os alunos das escolas parceiras.

Fonte: (DOSSIÊ DA COPA DO MUNDO DE CURITIBA, 2013, p. 16) adaptado pela autora

A análise do quadro remete a alguns questionamentos: como essas contrapartidas serão avaliadas? Será que já estão sendo avaliadas? Conforme o Dossiê da Copa do Mundo no município de Curitiba (2013, p. 16), "percebe-se que nenhuma das contrapartidas previstas para o Clube Atlético Paranaense significa o dispêndio de recursos na mesma proporção dos entes públicos, de forma que seria um equívoco chamá-las de 'contrapartidas'". É como se fosse um meio para mostrar que tal investimento público em uma instituição privada pudesse trazer algum retorno para a comunidade. Ao mesmo tempo, já se tem uma ideia de que passará despercebido pelos sujeitos, que mais uma vez não são informados do que ocorre no seu entorno. 
Diferentemente, em Porto Alegre não houve contrapartida entre estádio e prefeitura, pois a Prefeitura Municipal de Porto Alegre, por escolha, não investiu nos estádios. Esses tiveram como fonte principal o recurso do BNDES. A participação da prefeitura foi de forma direta na disponibilização de recursos para os clubes (DOSSIÊ DA COPA DO MUNDO DE PORTO ALEGRE, 2014).

Ainda a respeito da participação dos citadinos, destaca-se que foi criado, nas 12 cidades-sede do Brasil, o site "Copa Transparente", onde são disponibilizadas as informações à sociedade; o site é uma iniciativa para fiscalizar as obras da Copa do Mundo, e para consultar dados e documentos relacionados às obras (BONALUME, 2013).

Mesmo não considerando sujeitos participativos e informados do que ocorre nos espaços frequentados, os entrevistados concordam que a vinda da Copa do Mundo 2014, no geral, trouxe benefícios para as cidades, e os impactos econômicos e ambientais são positivos.

Quando se trata de megaeventos esportivos, Bahia (2013, p. 155) afirma que existe um consenso entre os pesquisadores da área, que consideram que as candidaturas "devem sinalizar, como prioridade de investimento, bem mais que o megaevento em si, apontando um planejamento de ações para toda a cidade/e ou país, que possa garantir uma rede complexa e articulada de benefícios". Outros estudos (MASCARENHAS, 2012; MASCARENHAS, 2011; VILLANO et al., 2008) também apontam que os megaeventos são considerados oportunidades benéficas para as cidades. No entanto, é notório que todos esses benefícios dependem, exclusivamente, da forma de planejamento, das prioridades que são estabelecidas pelas cidades-sede e como esses projetos são executados visando à melhoria dos espaços. Assim, tais pontos positivos variam de cidade para cidade.

O estudo de Radicchi (2012) apontou que a organização de um megaevento esportivo é um objetivo-chave que os governos têm como um catalisador da criação de valores para as economias dos países/cidades-sede. Portanto, é preciso ressaltar que tais eventos também podem remeter a desvantagens, principalmente quando os projetos não são concluídos.

Uma pesquisa realizado por Fressa, Rufino e Darino (2012) teve o objetivo de analisar o discurso do jornal Folha.com a partir das notícias relacionadas à realização da Copa do Mundo de Futebol 2014, no período de janeiro a março de 2011. Neste sentido, as 96 notícias foram categorizadas em "vantagens", que resultaram em $36,45 \%$, outros $56,25 \%$ das notícias abordaram as "desvantagens" e 7,30\% foram "neutras". Isso reflete na desaprovação por uma parte da sociedade.Vale ressaltar que essa pesquisa analisou dados de um jornal específico e que tais resultados devem ser tratados cuidadosamente.

Observa-se que as notícias que relatavam desvantagens quanto à realização da Copa do Mundo de Futebol no Brasil se sobressaíram. Em 2011, as notícias já previam muitos acontecimentos que foram concretizados meses antes da realização dos jogos, principalmente no que diz respeito aos atrasos das obras, além das indefinições, irregularidades, aumento de custos, dívidas e falta de planejamento. Para identificar se de fato as desvantagens se sobressaem em relação às vantagens, são necessários mais estudos originais acerca dos megaeventos esportivos no Brasil, principalmente no período pós-Copa.

No tocante às questões abertas do presente estudo, foram questionadas as mudanças positivas e negativas que ocorreram na região desde que a Copa do Mundo de Futebol foi anunciada. Os participantes da pesquisa realizada em Curitiba relataram que as mudanças 
positivas estão associadas à manutenção (melhoramento das vias, calçadas, iluminação, estética, ciclovia), à Praça Afonso Botelho e ao estádio Joaquim Américo. O Entrevistado 50 de Curitiba destaca a questão da estética e das mudanças que o evento traz, relatando que de "certa forma ajuda a população. E uma cidade bonita deixa a população feliz, o cidadão feliz, enfim. Apesar de faltar várias outras coisas, mas esse, 'up' que dá, digamos assim, na cidade já melhora, e repentina assim, já ajuda também". Nesse contexto, os aspectos positivos relatados pelo entrevistado contemplam o interesse e preocupação que muitas pessoas têm em relação à cidade onde moram por apresentar significados e relação com determinados espaços e o próprio futebol.

No que concerne à praça Afonso Botelho, as melhorias desse espaço de lazer estavam inseridas no projeto da Copa do Mundo 2014 de Curitiba. As melhorias descritas no projeto estavam relacionadas às melhorias no piso para promover mais acessibilidade, à nova pista de skate e caminhada, ao playground, às quadras esportivas, à academia ao ar livre, aos deques de madeira para área de permanência ou outras atividades. Mas, no período em que foram feitas as observações, a praça estava interditada por reforma, e era nítido que não estaria pronta a tempo para os jogos. Conforme o site da prefeitura de Curitiba (2015), a reforma foi dividida em duas etapas, uma antes dos jogos (Foto 1), quando foi construído o piso técnico, e a segunda iniciou no ano de 2015.

Foto 1 - Reforma da Praça Afonso Botelho Antes da Copa do Mundo 2014

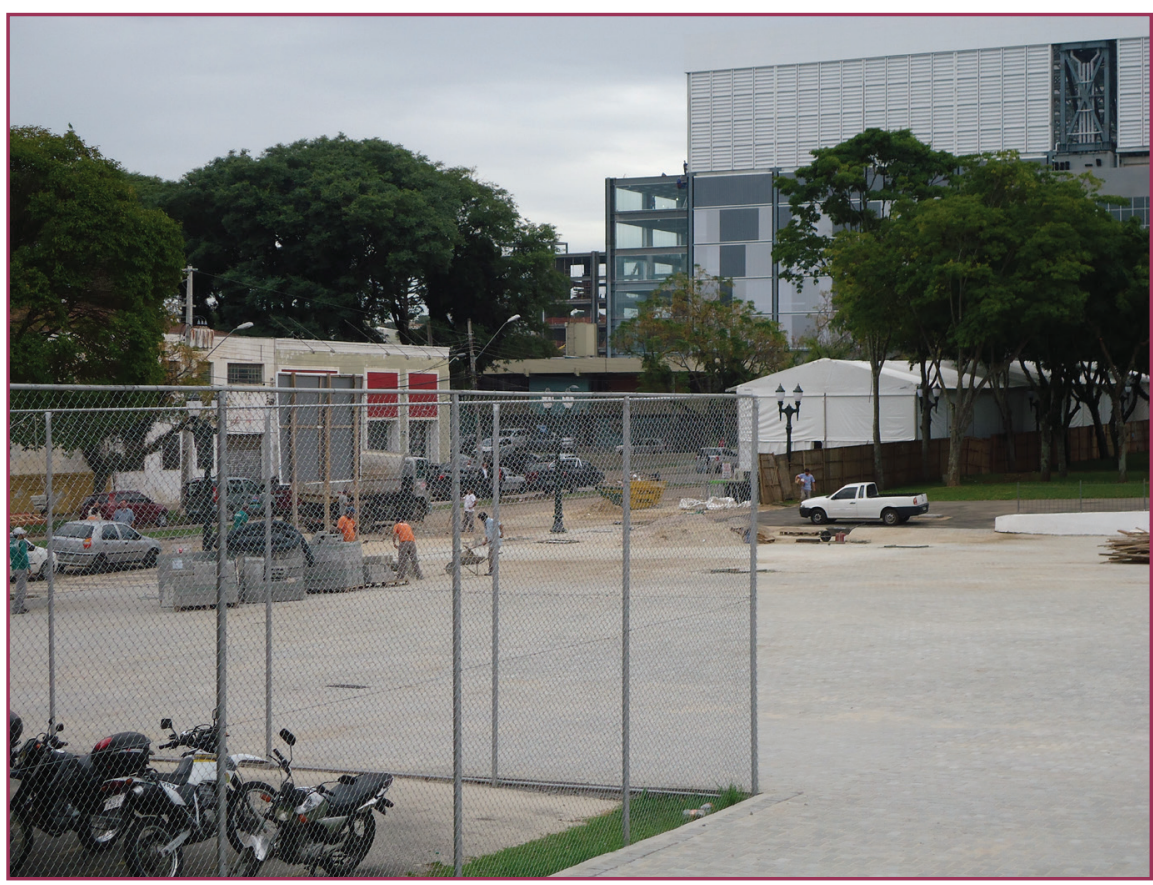

Fonte: Arquivo pessoal (maio/2014)

Embora a Praça Afonso Botelho estivesse cercada no período que antecedia os jogos, era comum encontrar alguns usuários dentro dela. Outros sujeitos passaram a frequentar 0 entorno da praça ou mesmo a utilizar outras praças que se localizam perto da Joaquim Américo como, por exemplo, a Praça Oswaldo Cruz. Essa praça não estava nas obras planejadas para a Copa do Mundo 2014, mesmo estando próxima ao estádio e necessitando de uma reforma urgente. Mesmo assim, em todos os horários em que foram feitas as observações, havia sempre sujeitos de diferentes idades realizando diversas práticas corporais, ou mesmo 
vivências de lazer, como encontro com amigos, leituras e passeio com crianças. Ressalta-se que em fevereiro de 2015 a prefeitura de Curitiba autorizou o início da reforma nessa praça.

As mudanças negativas citadas pelos sujeitos de Curitiba foram as questões do trânsito, falta de investimento na saúde, falta de planejamento e gasto público. O Entrevistado 46 da cidade de Curitiba frisou alguns transtornos:

\begin{abstract}
o trânsito, que se criou e as complicações que se deram nas outras vias por conta dessas obras, foram terríveis. Porque não tiveram outras vias de fluxo, então você pega a via principal que era a Getúlio Vargas, que passa na frente do estádio, não tinha outra via de fluxo que seria a de cima, Silva Jardim, não conseguiu comportar. Tem muito trânsito, você leva mais que o dobro do tempo, então você realmente não tem mobilidade, na questão de trânsito. Não sei como vai ser depois, pois não foram alargadas as ruas.
\end{abstract}

De acordo com as observações realizadas para o presente estudo, não houve alargamento das ruas nesse trecho citado pelo Entrevistado 46. Todavia, em outros trechos ocorreram, o que beneficiou algumas pessoas. Em contrapartida, o mesmo sujeito destacou que "teve uma melhoria na questão de piso, realmente o asfalto tá muito melhor, as calçadas foram, não sei se reformadas por completo, mas pelo menos recolocadas pelo que eu acompanhei das obras". Já o Entrevistado 38, também de Curitiba, destacou que "é melhoria para a cidade, alguma coisa de positivo têm. Eu acho que é positivo, só os gastos que deveriam ser menores".

Ressalta-se que o alargamento das ruas não é a única forma de melhorar o trânsito na cidade, obviamente é preciso investir em transporte público. Na verdade, essa questão do trânsito é um problema antigo no Brasil. Conforme Freitag (2012), no Brasil, na segunda metade do século XX, a prioriadade era arranha-céus e túneis que beneficiavam o transporte urbano, principalmente o automóvel. Já na França, por exemplo, a prioridade foi o transporte público. De acordo com Freitag, como o Brasil deu preferência ao transporte rodoviário, multiplicou-se o uso de carros particulares, consequentemente diminuindo espaço da calçada para o pedestre. Quando se refere a megaeventos esportivos, é comum que um dos relatos é que pode melhorar o transporte público (CASHMAN, 2002), embora nem sempre esses benefícios abranjam toda a população. Analisando a fala dos sujeitos e os projetos da Copa do Mundo de Futebol, surge o sentimento de que a prioridade continua sendo para os carros particulares.

É por isso que, ao analisar as mudanças referentes ao sistema de transporte que ocorreram na Copa do Mundo da Alemanha, em 2006, percebe-se que, como as cidades já tinham um bom sistema de transporte, grande parte dos projetos que foram executados tinha o intuito de modernizar e adequar as infraestruturas que já existiam (BRANKIS et al., 2013).

Em Porto Alegre, os resultados não foram diferentes, quando comparados aos de Curitiba. No tocante às mudanças positivas, os pesquisados ressaltaram a manutenção (melhoria das vias e pavimentação), o estádio Beira-Rio e a estética da cidade. Em Porto Alegre, os sujeitos participantes enfatizaram as modificações relacionadas ao alargamento das vias, mas também destacando os transtornos pelo trânsito e pelas obras inacabadas. De acordo com o Dossiê da Copa do Mundo de Porto Alegre (2014, p. 59), esses projetos prioritários de infraestrutura foram determinados como prioritários em função da mobilidade necessária para a Copa. Ou seja, a maioria das obras foram planejadas para as áreas 
centrais, onde já havia certa estrutura e serviços urbanos. Conforme o dossiê, "em grande medida proporcionou uma melhor mobilidade aos turistas e espectadores dos jogos nos acessos aos 'territórios da FIFA'".

Em Porto Alegre, próximo ao estádio Beira-Rio também há um espaço de lazer. O parque Marinha do Brasil. Embora estivesse cerca do estádio, não passou por grandes melhorias devido às obras da Copa (Foto 2).

Foto 2: Parque Marinha do Brasil

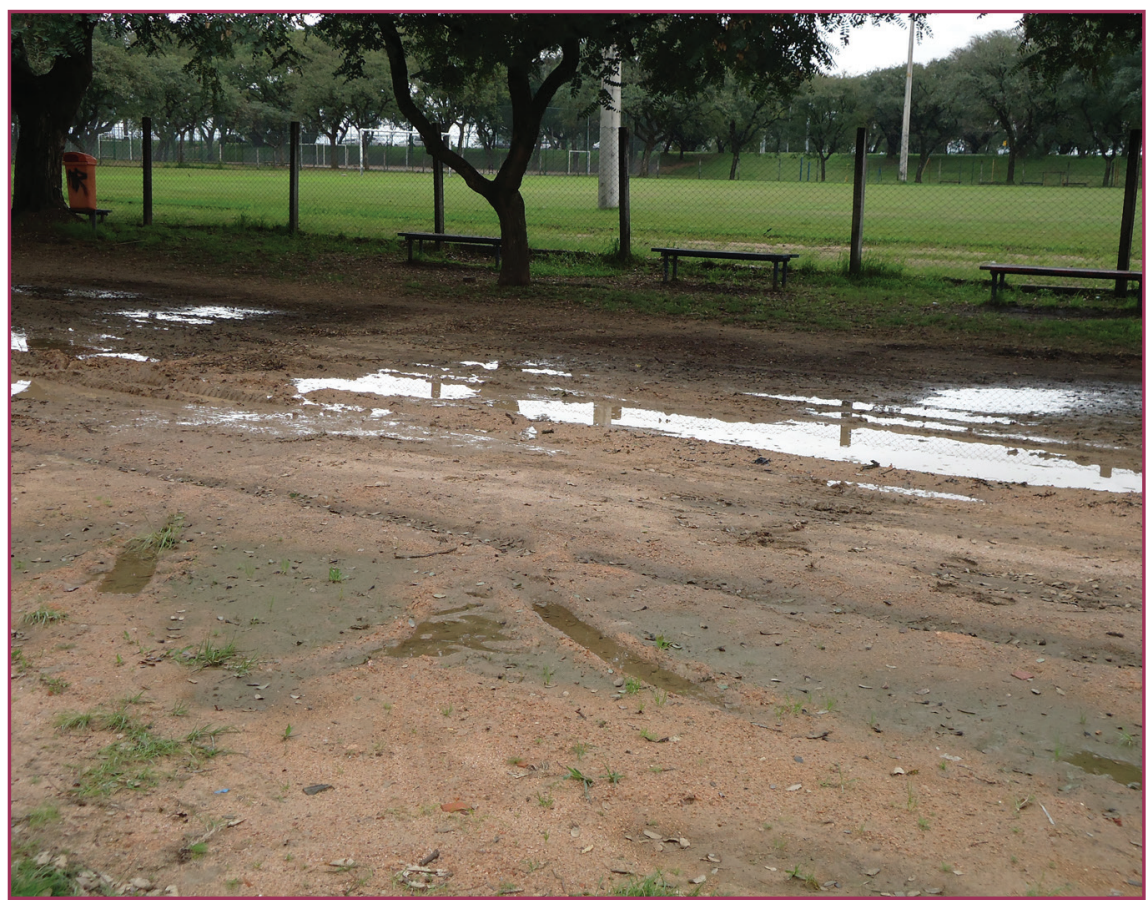

Fonte: Arquivo Pessoal (Julho/2015)

Os megaeventos esportivos são reconhecidos por acelerar o desenvolvimento urbano, contudo, frequentemente, muitos dos projetos que são planejados não são executados parcial ou totalmente (SMITH, 2012). Smith (2012) destaca que os megaeventos podem ser um meio de assegurar que os projetos ambiciosos de desenvolvimento urbano comecem, mas não garantem que serão finalizados antes do evento e até mesmo depois.

Durante as observações, foi percebido que havia muito trânsito no entorno do estádio, porque algumas vias estavam interditadas. Uma dessas dificuldades do trânsito pode ter sido ocasionada pelo fato de o estádio Beira-Rio estar localizado ao lado do rio Guaíba, restringindo as vias que dão acesso a ele. Mesmo assim, o Entrevistado 3 da cidade de Porto Alegre relatou que a vinda do megaevento "é positiva porque depois que a Copa for embora, que as reformas acabarem, vai ficar tudo bonito e tudo para a cidade. Ruim pelos transtornos que está causando no momento pelos engarrafamentos". O mesmo indivíduo ressalta que "as avenidas estão sendo reasfaltadas, o Beira-Rio foi todo reformado, todo melhorado".

O Entrevistado 24 respondeu que tais obras geraram alguns transtornos, relatando "mudanças estruturais que no primeiro momento geraram alguns transtornos de trânsito, dificuldade de chegada, as obras que, quando chove principalmente, traz problemas, mas que depois da Copa do Mundo, esperamos que tudo isso se estabilize". (Foto 3). 
Foto 3: Entorno Estádio Beira-Rio (Porto Alegre)

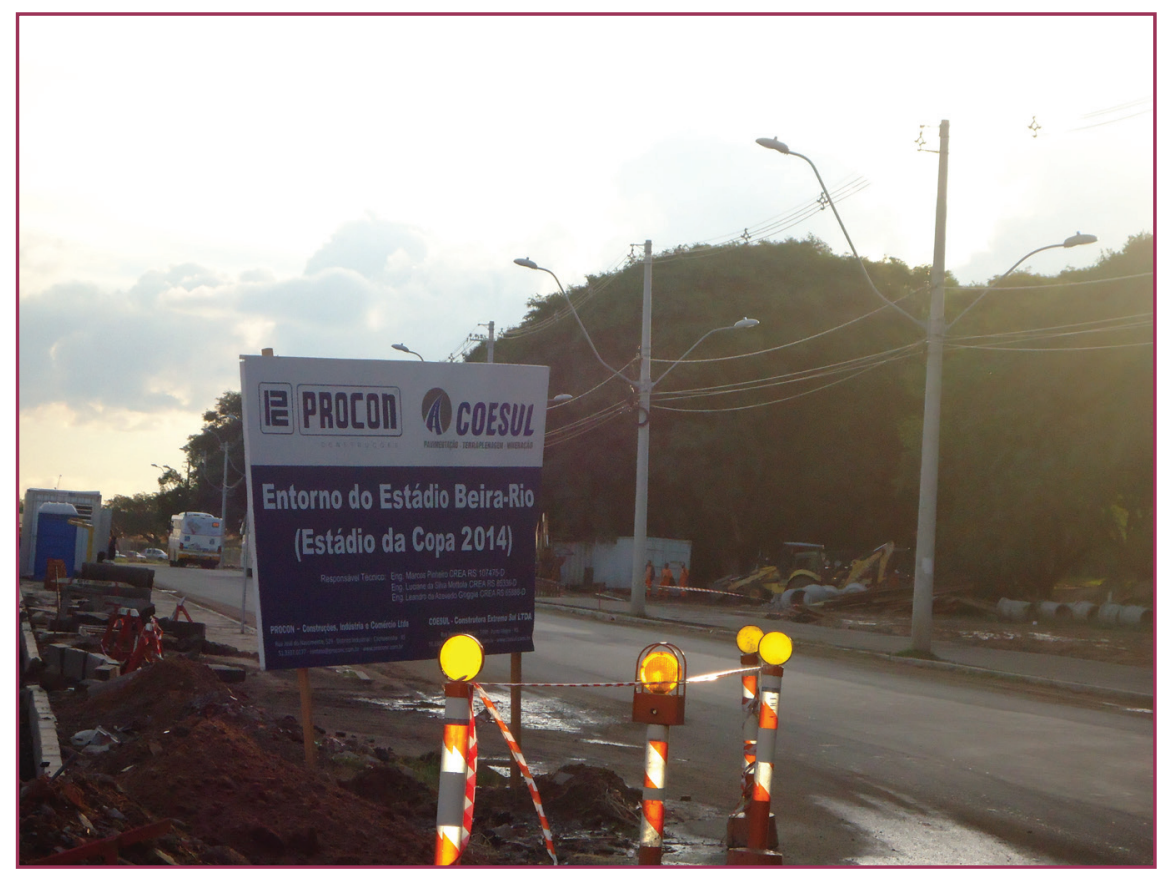

Fonte: Arquivo pessoal (Maio/ 2014).

Bernasconi (2013) destaca que apenas em janeiro de 2010 o Ministério do Esporte divulgou a lista com as obras relacionadas à Copa do Mundo de Futebol 2014, junto a ela, estava a versão da matriz de responsabilidade. Depois da divulgação, houve algumas revisões e modificações. No que abrange a mobilidade urbana, o autor trata como uma "imobilidade", visto a demora nas definições dos projetos, o que resultou em obras adiadas (para o pós-Copa) ou não realizadas. Ressalta-se que a presente pesquisa foi realizada antes da Copa do Mundo e os sujeitos já ressaltavam os gastos públicos e as obras inacabadas.

Esses dados remetem para a importância de um planejamento no período que antecede a realização dos jogos. Além disso, chama atenção a singularidade de ouvir os sujeitos, seus respectivos posicionamentos no tocante às mudanças que ocorrem na cidade. Destaca-se que não se pode culpar apenas a organização do evento quanto à falta da participação popular, pois isso pode ser consequência da população não ter uma educação voltada a reivindicar, participar de reuniões e audiências públicas. Neste caso, é preciso reconhecer que são necessários maiores estímulos para que a sociedade se motive a participar e acompanhar o processo concernente à gestão pública, seja em tempos de megaeventos, seja também para outros fins.

Isso seria uma estratégia para que os projetos fossem pensados e executados em parceira com diferentes atores sociais, entre eles moradores, gestores públicos, pesquisadores, líderes comunitários, entre outros. Desta forma, sediar um megaevento esportivo poderia trazer muito mais benefícios para as cidades-sede relacionados aos aspectos políticos, econômicos e sociais.

\section{CONSIDERAÇÕES FINAIS}

As mudanças que ocorreram no entorno dos estádios-sede da Copa do Mundo de Futebol 2014, na Região Sul do Brasil, remetem à infraestrutura, principalmente no que diz 
respeito ao alargamento das ruas, trânsito, benefícios para cidades-sede no geral, além de poder trazer uma imagem positiva para a cidade. Cabe destacar que não se pode considerar de fato essas características como legado, até porque o presente estudo foi realizado no período que antecedeu a Copa do Mundo de 2014.

Em relação aos espaços e equipamentos de lazer, percebeu-se que as mudanças se restringem aos estádios que são privados e algumas melhorias dos espaços que estão próximos aos espaços, destacando a Praça Afonso Botelho, em Curitiba. Ressalta-se que, embora as intervenções nos espaços públicos de lazer não sejam uma exigência para sediar a Copa do Mundo, questiona-se a importância dessas intervenções, até porque um dos possíveis legados esperados é que os brasileiros tenham mais interesse em praticar algum tipo de atividade física e, para que esse legado seja efetivado, é preciso espaços adequados para essas vivências.

Uma das limitações do estudo foi a discussão se tratar apenas da Região Sul do Brasil, o que pode ser sugestões de futuros estudos para tratar das demais regiões, principalmente para identificar o que de fato ficou como legado e o que se pode tirar de positivo e de lição, de um país em desenvolvimento, como o Brasil, realizar tal evento.

\section{REFERÊNCIAS}

ALMEIDA, Juvêncio. A Copa do Mundo no Brasil: implicações no campo dos direitos humanos. Jus Navigandi, Teresina, v. 18, n. 3626, p. 1-2, 2013.

BAHIA, Mirleide Chaar. Legados socioambientais. In: MARCELLINO, Nelson Carvalho. Legados de megaeventos esportivos. Campinas: Papirus, 2013. p. 248-268.

BERNASCONI, José Roberto. Legados para a infraestrutura. In: MARCELLINO, Nelson Carvalho. Legados de megaeventos esportivos. Campinas: Papirus, 2013. p. 139-153.

BONALUME, Cláudia Regina. Legados para o controle social em políticas públicas de esporte e lazer. In: MARCELLINO, Nelson Carvalho. Legados de megaeventos esportivos. Campinas: Papirus, 2013. p. 35-58.

BRASIL- LIBERDADE E DEMOCRACIA. Em 1979 governo brasileiro vetou a Copa do Mundo. Disponível em: <http://brasillivreedemocrata.blogspot.com.br/2014/01/em-1979-governo-brasileirovetou-copa.html>. Acesso em: 12 out. 2015.

BORJA, Jordi. Luces y sombras del urbanismo de Barcelona. Barcelona: UOC, 2010.

BRASIL. Conselho Nacional de Saúde. Resolução 466/12. Brasília, DF, 2012. Disponível em: <http:// conselho.saude.gov.br/resolucoes/2012/Res0466.pdf>. Acesso em: 2015.

BRANSKI, Regina Meyer et al. Infraestruturas nas copas do mundo da Alemanha, África do Sul e Brasil. Cadernos Metrópole, São Paulo, v. 15, n. 30, p. 557-582, 2013.

CASSOU, Ana Carina Naldino. Características ambientais de utilização e nível de atividade física dos usuários de parques e praças de Curitiba, PR. 2009. 153f. -Dissertação (Mestrado) Universidade Federal do Paraná, Curitiba, 2009.

CASHMAN, Richard. El impacto de los juegos em las sedes olímpicas. Barcelona: Centre d'Estudis Olímpics (UAB). Cátedra Internacional de Olimpismo (CIO-UAB). 2002.

COHEN, Deborah et al. Contribution of parks to physical activity. American Journal of Public Health, Birmingham, v. 97, n. 3, p. 509-514, mar. 2007. 
COLLET, Carine et al. Fatores determinantes para a realização de atividades físicas em parque urbano de Florianópolis. Revista Brasileira de Atividade Física e Saúde, Pelotas, v. 13, n. 1, p. 15-23, 2008.

CONCHAS, Miguel. Research possibilities for the 2014 FIFA world cup in Brazil. Soccer \& Society, Abingdon, v. 15, n. 1, p. 167-174, 2014.

CONHEÇA os efeitos da Copa e da Olimpíada na economia dos países. Disponível em: <http:// economia.ig.com.br/conheca-os-efeitos-da-copa-e-da-olimpiada-na-economia-dos-paises/ n1597563440108.html>. Acesso em: 12 out. 2015.

CURITIBA. Prefeitura abre licitação para segunda etapa de obras na Praça Afonso Botelho. Disponível em: <http://www.curitiba.pr.gov.br/noticias/prefeitura-abre-licitacao-para-segunda-etapa-deobras-na-praca-afonso-botelho/33873>. Acesso em: 28 abr. 2015.

DATAFOLHA. Opinião sobre protesto e Copa do Mundo. 2014. 18 e 20 fev. 2014. Disponível em: $<$ http://media.folha.uol.com.br/datafolha/2014/02/24/opiniao-sobre-protestos-e-copa-do-mundo.pdf> Acesso em: 15 maio 2015.

DOSSIÊ DA ARTICULAÇÃO NACIONAL DOS COMITÊS POPULARES DA COPA. Megaevento e violações de direitos humanos no país. 2012. Disponível em: <http://www.apublica.org/wp-content/ uploads/2012/01/DossieViolacoesCopa.pdf>. Acesso em: 21 out. 2014.

FIRKOWSKI, Olga. O legado dos Megaeventos. Revista Ciência Hoje, São Paulo, p. 6-8, 2014. Disponível em: <http://cienciahoje.uol.com.br/revista-ch/2014/311/o-legado-dos-megaeventos>. Acesso em: 2 jul. 2014.

FLICK, Uwe. Introducción a la investigación cualitativa. Madrid: Morata, 2012.

FONTANELLA, Bruno José Barcellos. Amostragem em pesquisas qualitativas: propostas de procedimentos para constatar saturação teórica. Caderno de Saúde Pública, Rio de Janeiro, v. 27, n. 2, p. 289-394, 2011.

FONTANELLA, Bruno José Barcellos; RICAS, Janete; TURATO, Egberto Ribeiro. Amostragem por saturação em pesquisas qualitativas em saúde: contribuições teóricas. Cadernos de Saúde Pública, Rio de Janeiro, v. 24, n. 1, p.17-27, 2008.

FREITAG, Bárbara. Teorias da cidade. Campinas: Papirus, 2012.

FRESSA, Leonardo Gonsalles; RUFINO, Luiz Gustavo Bonatto; DARIDO, Suraya Cristina. Vantagens e desvantagens da copa do mundo no Brasil: análise a partir do discurso do jornal Folha.com. Revista Mackenzie de Educação Física e Esporte, São Paulo, v. 11, n. 1, p. 107-124, 2012.

GRAEFF, Billy et al. Relatório de Pesquisa: o impacto da Copa do Mundo de Futebol FIFA 2014 na cidade de Porto Alegre: a percepção de comunidades afetadas. Porto Alegre: UFRGS, 2015. Disponível em: <http://www.ufrgs.br/ceo/arquivos/IMPACTO\%20DA\%20COPA\%202014\%20-\%20 Relatorio\%20da\%20Pesquisa\%20Interinstitucional.pdf>. Acesso em: 12 out. 2015.

HEINEMANN, Klaus. Introducción a la metodología de la investigación empírica- en las ciencias del deporte. Badalona: Paidotribo, 2008.

HORNE, John; MANZENREITER, Wolfram. An introduction to the sociology of Sport mega-events. Sociological Review, Londres, v. 2, n. 52, p. 1-24, 2006.

JACQUES, Paola Berenstein. Patrimônio Cultural Urbano: espetáculo contemporâneo? Revista de Urbanismo e Arquitetura, Salvador , v. 8, p. 33-39, 2003.

MASCARENHAS, Fernando. Megaeventos esportivos e educação física: alerta de tsunami. Movimento, Porto Alegre, v. 18, n. 1, p. 39- 67, 2012.

MASCARENHAS, Gilmar. Desenvolvimento urbano e grandes eventos esportivos: o legado olímpico nas cidades. In: MASCARENHAS, Gilmar; BIENENTEIN, Glauco; SÁNCHEZ, Fernanda. 0 jogo continua: megaeventos esportivos e cidades. Rio de Janeiro: EdUERJ, 2011. p. 27-39. 
PREUSS, Holger. The conceptualization and measurement of mega sports event legacies. Journal of Sport and Tourism, Canterbury, v. 12, n. 3-4, p. 207-228, 2007.

RADICCHI, Elena. Megaeventos deportivos y creación de valor para las economias anfitrionas. In: GOIG, Ramón Llopis Megaeventos deportivos: perspectivas y estudios de casos. Barcelona: UOC, 2012. p. 25- 51.

RECHIA, Simone; SILVA, Emília Amélia Pinto Costa. Espaços públicos de lazer em época de megaeventos esportivos: entre o sonho mais dourado e a realidade mais cruel. In: MARCELLINO, Nelson Carvalho. Legados de megaeventos esportivos. Campinas: Papirus, 2013. p. 197-220.

RECHIA, Simone; BETRÁN, Javier Olivera. Parques urbanos de Barcelona: relação entre usos principais e combinados, a diversidade nas formas de apropriação e segurança. Movimento, Porto Alegre, v. 16, n. 3, p. 181-202, 2010.

ROLNIK. Raquel. Removidos pelos megaeventos são os últimos a saber. 2011. Disponível em: <http:// www.viomundo.com.br/entrevistas/raquel-rolnik-removidos-pelos-megaeventos-sao-os-ultimos-asaber.html>. Acesso em: 16 out. 2014.

ROTTA, Ana Mara Soletti; PIRES, Giovani de Lorenzi. "Se essa praça, se essa praça fosse nossa...": espaços públicos e possibilidades para o lazer dos jovens de Caçador/SC. Licere, Belo Horizonte, v. 13, n. 2, p. 1-22, jun. 2010.

SANTOS, Edmilson Santos. Perfil dos usuários do Parque Esportivo Eduardo Gomes/ Canoas/RS. Arquivos em Movimento, Rio de Janeiro, v. 3, n. 1, p. 70-86, jan./jun. 2007.

SEVERINO, Antônio Joaquim. Metodologia do trabalho científico. São Paulo: Cortez, 2007.

SILVA, Diego Augusto Santos; PETROSKI, Edio Luiz; REIS, Rodrigo Siqueira. Barreiras e facilitadores de atividades físicas em frequentadores de parques públicos. Motriz, Rio Claro, v. 15, n. 2, p. 219-227, abr.jjun. 2009.

SILVA, Emília Amélia Pinto Costa. 0 lugar de lazer na cidade: um espaço de diálogo e de vivências. 2011. 87f. Dissertação (Mestrado) - Curso de Educação Física, Universidade de Pernambuco/ Universidade Federal da Paraíba, Recife, 2011.

SMITH, Andrew. Megaeventos deportivos y desarrolo urbano. In: GOIG, Ramón Llopis. Megaeventos deportivos: perspectivas y estúdios de casos. Barcelona: UOC, 2012. p. 75- 96.

SUÉCIA recusa Jogos de 2022 para não usar dinheiro público. Disponível em: <http://exame.abril. com.br/mundo/noticias/suecia-recusa-jogos-de-2022-para-nao-usar-dinheiro-publico>. Acesso em: 12 out. 2015.

VILLANO, Bernardo et al. Seminário "gestão de legados de megaevento esportivos": pontos de convergência. In: DACOSTA, Lamartine et al. (Org.). Legados de megaeventos esportivos. Brasília: Ministério do Esporte, 2008. p. 47-50. 
Apoio: Capes e CNPq

(J) Movimento, Porto Alegre, v. 22, n. 1, 293-310, jan./mar. de 2016. 